\title{
Assessment of background radiation levels in the southeast of Iran
}

\author{
Mohammad Haghparast ${ }^{1,2}$, Mahdieh Afkhami Ardekani*2 (D), Mahmoud Navaser ${ }^{1}$, Soheila Refahi ${ }^{3}$, Milad Najafzadeh $^{2}$, \\ Hamed Ghaffari*1(D), Mahboubeh Masoumbeigi ${ }^{4}$
}

Received: 25 Sep 2019

Published: 1 Jun 2020

\section{Abstract}

Background: Measuring background radiation (BR) is highly important from different perspectives, especially from that of human health. This study was conducted to measure BR in the southeast of Iran.

Methods: BR was measured in Hormozgan and Sistan-Bluchestan provinces using portable Environmental Radiation Meter Type 680 detector. The average value was used to calculate the absorbed dose rate and indoor annual effective dose (AED) from BR. In addition, excess lifetime cancer risk (ELCR) was evaluated.

Results: The results showed that the maximum and minimum absorbed dose rates were 71.9 and 34.2 nGy.h-1 in Abomoosa and Minab in Hormozgan province and 90.0 and 47.8 nGy.h-1 in Zahedan and Chabahar in Sistan-Bluchestan province, respectively. Data indicated that these areas had a lower BR level compared with the worldwide level. The ELCR from indoor AED was larger compared with the worldwide average of $0.29 \times 10-3$.

Conclusion: This study provided a reference for designing and developing specific regional surveys associated with the measurement of natural BR in the southeast of Iran.

Keywords: Background radiation, Environmental radiation, Absorbed dose rate, Annual effective dose

Conflicts of Interest: None declared

Funding: None

\section{*This work has been published under CC BY-NC-SA 1.0 license. \\ Copyright $\bigcirc$ Iran University of Medical Sciences}

Cite this article as: Haghparast M, Afkhami Ardekani M, Navaser M, Refahi S, Najafzadeh M, Ghaffari H, Masoumbeigi M. Assessment of background radiation levels in the southeast of Iran. Med J Islam Repub Iran. 2020 (1 Jun);34:56. https://doi.org/10.47176/mjiri.34.56

\section{Introduction}

Humans are exposed to ionizing radiation from natural radioactivity, but natural radioactivity sources are present all over the earth $(1,2)$. Approximately $82 \%$ of human absorbed radiation doses are out of control and stem from natural sources. Gamma radiation emitted from these sources (background radiations (BRs)) is due to substantial primordial radionuclides. The altitude, percent of nuclei in the soil, and the geographical conditions of

Corresponding author: Mahdieh Afkhami Ardekani, m.afkhami87@gmail.com Hamed Ghaffari, hamedghaffari@yahoo.com

1. Department of Medical Physics, School of Medicine, Iran University of Medical Sciences, Tehran, Iran

2. Department of Radiology, Faculty of Paramedicine, Hormozgan University of Medical Sciences, Bandar-Abbas, Iran

3. Department of Medical Physics, Faculty of Medicine, Ardabil University of Medical Sciences, Ardabil, Iran

4. Department of Medical Physics \& Biomedical Engineering, School of Medicine, Tehran University of Medical Sciences, Tehran, Iran different regions are main sources of BR fluctuation (3). BR measurement is one of the vital aspects of health physics $(4,5)$. The resident's exposure dose rate is assessed using the outdoor and indoor dose rates and the number of hours of outdoor activity (6).

Major sources of BR fall into 3 groups: (a) cosmic, (b) terrestrial, and (c) cosmogenic radiations, which are caused by cosmic ray interactions (3). At the earth surface,

$\uparrow$ What is "already known” in this topic:

Understanding natural background radiation level, as the major source of human exposure to ionizing radiation is important because of its impact on health. A number of studies have assessed natural background radiation level in many countries.

$\rightarrow$ What this article adds:

In this study, data showed that all cities in the 2 provinces of Hormozgan and Sistan-Bluchestan had a lower background radiation than the worldwide level. This study can be used as a reference for research design and development of regional surveys associated with the measurement of natural background radiation in the southeast of Iran. 
BRs are mainly derived from very high concentrations of radium and its decay product, which is brought to the earth's surface by hot springs, or from high thorium concentrations, which are found at the travertine deposits (7). With regards to the presence of numerous hot springs in Ramsar (Iran), this area has various concentrations of radioactivity (7). Nevertheless, other parts of the world have different levels of BR such as kerala in India (8), Xiazhuang in China (9), and Costal red sea in Egypt (10).

One should not overlook the fact that the geographical properties of an area such as latitude and altitude have a decisive role in the distribution of external exposure owing to terrestrial radiation $(11,12)$. In general, the BR dose rates from cosmic rays depend on latitude to some extent and on altitude to a great extent. The effect of latitude is due to natural charged particles from the early cosmic rays and the effect of Earth's magnetic field, which strongly absorb cosmic rays; and with the change in latitude, the intensity of these beams from the equator rises toward the poles $(3,4)$.

Natural radiation is considered as the main source of human exposure; thus, studies on the dose from this source and its effects on health are of great value as a reference when considering standard and regulatory control actions on radiation protection. Interest in this type of study has led to many national surveys on natural radiation over the last decade $(11,13,14)$.

Natural radiation contributes to about $94 \%$ of people's exposure in developing countries such as Iran (7). Also, planning to control cancer incidence and treatment methods in the future requires accurate information about BR. Thus, the program of natural radiation quantitation was formed by the Atomic Agency of Iran. The aim of this study was to investigate natural $\mathrm{BR}$ and provide a map of ambient gamma BR in Hormozgan and SistanBluchestan provinces to estimate indoor annual effective dose $\left(\mathrm{AED}_{\text {indoor }}\right)$ of residents in these areas. In addition, excess lifetime cancer risk (ELCR) associated with the exposure was computed for each designated location.

\section{Methods}

Hormozgan and Sistan-Bluchestan provinces are located in the southeast of Iran. A topographic map of both provinces was obtained from the Civil Engineering Organization of the state. A total of 9 cities in Hormozgan and 7 in Sistan-Bluchestan were selected to determine the dose rate of gamma BR. Each city was divided into 5 main areas: north, east, west, south, and center. For each of the areas, we randomly selected 5 buildings and measured indoor BR. The city center was considered as a reference point for measurements; then, additional buildings were selected in north-south and east-west directions, with an appropriate distance from each other. The BR measurements were performed using portable environmental radiation meter type 6-80 detector (mini instrument Inc, Finland), calibrated by standard sources of ${ }^{60} \mathrm{Co}$ and ${ }^{226} \mathrm{Ra}$ in Iran Atomic Energy Agency. The BR measurements were done by holding the detector at least 6 meters away from any building or wall and 1 meter above the ground surface in flat areas to diminish their effects on the radiation field. For each measurement, we considered the total exposure time of 1 hour. The mean of the measurements in each building were computed and considered as indoor absorbed dose of that building. Finally, the results of this study were compared with world quantities. The values of the absorbed dose rate were used to calculate indoor AED rate considering some correction factors. In addition, AED from BR was obtained as follows $(15,16)$ :

$\mathrm{AED}_{\text {indoor }}\left(\mathrm{mSv} \cdot \mathrm{y}^{-1}\right)=$ Absorbed dose rate $(\mathrm{nGy} / \mathrm{h}) \times \mathrm{T}$ (h) $\times 0.8 \times 0.7 \mathrm{~Sv} / \mathrm{Gy}$

where AED is the annual effective dose $\left(\mathrm{mSv} \cdot \mathrm{y}^{-1}\right)$ and T the time converter from hour to year $(8760 \mathrm{~h})$. The AED was determined using the indoor occupancy factor of 0.8 . The occupancy factor is defined as the proportion of the total time during which an individual is exposed to a radiation field. The dose conversion coefficient used was $0.7 \mathrm{~Sv} / \mathrm{Gy}$ to convert the absorbed dose in air to the effective dose in humans, as reported by UNSCEAR 2000 (17).

The ELCR was calculated using the following formula: $\mathrm{ELCR}=\mathrm{AED} \times \mathrm{DL} \times \mathrm{RF}$

where AED is annual effective dose, DL the average lifespan (70 years), and RF the risk factor $\left(\mathrm{Sv}^{-1}\right)$, showing the fatal cancer risk per Sievert. For stochastic effects from low-dose BR, ICRP 103 suggested the value of 0.057 for public exposure (ICRP, 2007).

\section{Results}

The results of absorbed dose rate of gamma BR in air and corresponding AED rates are presented in Table 1 for Hormozgan and Sistan-Bluchestan provinces. For each selected area, mean \pm standard deviation (SD) of the measurements was calculated. According to Table 1, the maximum and minimum absorbed dose rates were 71.9 and $34.2 \mathrm{nGy}^{-1} \mathrm{~h}^{-1}$ in Abomoosa and Minab in Hormozgan province and 90.0 and $47.8 \mathrm{nGy}^{-1}$ in Zahedan and Chabahar in Sistan-Bluchestan province, respectively. Excess average lifetime cancer risk in Hormozgan and Sistan-Bluchestan province was $0.81 \times 10^{-3}$ and $1.3 \times 10^{-3}$, respectively.

\section{Discussion}

Based on the findings of this study, the interaction of ionizing radiation with tissues can cause multiple complications such as DNA damage and cancer (18). Researchers across the globe are interested in measuring BR (19, 20). Many researchers have widely used BR quantities to investigate mean activity concentrations of radioactive elements such as ${ }^{232} \mathrm{Th},{ }^{238} \mathrm{U}$, and ${ }^{40} \mathrm{~K}$ in the earth's crust, which can be found in the following situations: (1) minerals (eg, monazites and zircons) (21); distribution of source-rock materials (eg, elevated level of radionuclides) (22); radioactivity in local soil and food (22), distribution of nuclear mineral resources at offshore areas for sea floor mapping (23); the temporal variation of radon concentration at indoor area (24); the high level of natural radioactivity of granite, which is used as a building material (25).

In this study, absorbed dose rates and corresponding 
Table 1. Absorbed dose rate $\left(\mathrm{nSv} \cdot \mathrm{h}^{-1}\right)$, annual effective dose (mSv.year $\left.{ }^{-1}\right)$, and excess lifetime cancer risk (ELCR) at the locations

\begin{tabular}{|c|c|c|c|}
\hline City & $\begin{array}{c}\text { Absorbed dose rate }\left(\mathrm{nGy}^{-1}\right) \\
\text { Mean } \pm \text { SD }\end{array}$ & $\begin{array}{c}\text { Effective dose rate }\left(\mathrm{mSv} \cdot \mathrm{y}^{-1}\right) \\
\text { Mean } \pm \text { SD }\end{array}$ & $\mathrm{ELCR} \times 10^{-3}$ \\
\hline \multicolumn{4}{|c|}{ Hormozgan province } \\
\hline Bandar Abbas & $35.0 \pm 2.3$ & $0.17 \pm 0.01$ & 0.67 \\
\hline Minab & $34.2 \pm 0.8$ & $0.16 \pm 0.04$ & 0.64 \\
\hline Qeshm & $34.4 \pm 4.9$ & $0.17 \pm 0.02$ & 0.67 \\
\hline Roodan & $41.4 \pm 7.2$ & $0.20 \pm 0.03$ & 0.80 \\
\hline Abomoosa & $71.9 \pm 35.9$ & $0.35 \pm 0.17$ & 1.40 \\
\hline Hagiabad & $45.4 \pm 1.8$ & $0.22 \pm 0.01$ & 0.88 \\
\hline Lenkeh & $57.2 \pm 12.9$ & $0.28 \pm 0.06$ & 1.11 \\
\hline Bastak & $58.1 \pm 9.9$ & $0.28 \pm 0.05$ & 1.11 \\
\hline Jask & $35.2 \pm 3.1$ & $0.17 \pm 0.01$ & 0.67 \\
\hline \multicolumn{4}{|c|}{ Sistan-Bluchestan province } \\
\hline Zabol & $54.0 \pm 13.6$ & $0.26 \pm 0.07$ & 1.04 \\
\hline Zahedan & $90.0 \pm 11.0$ & $0.44 \pm 0.05$ & 1.76 \\
\hline Khash & $81.4 \pm 11.5$ & $0.40 \pm 0.05$ & 1.60 \\
\hline Saravan & $79.0 \pm 6.5$ & $0.40 \pm 0.03$ & 1.60 \\
\hline Iranshahr & $49.2 \pm 5.4$ & $0.24 \pm 0.03$ & 0.96 \\
\hline Nikshahr & $64.0 \pm 3.9$ & $0.31 \pm 0.02$ & 1.23 \\
\hline Chabahar & $47.8 \pm 8.9$ & $0.23 \pm 0.04$ & 0.92 \\
\hline
\end{tabular}

AED rates were determined for cities of Hormozgan and Sistan-Bluchestan provinces. As presented in Table 1, the mean indoor AED from BR in all cities of Hormozgan and Sistan-Bluchestan provinces were lower than the worldwide mean of the AED of $0.48 \mathrm{mSv}$ reported by UNSCEAR (17). Thus, it can be reasonably argued that this level of effective dose does not impose considerable health problems to the residents. A study by Ajayi et al reported that the average radiation dose rate in some parts of Nigeria is $0.53 \mathrm{mSv}_{\mathrm{y}} \mathrm{y}^{-1}(26)$. In Egypt, Har b et al measured the natural BR level and found it to be 0.05 $\mathrm{mSv} \cdot \mathrm{y}^{-1}(10)$. In another study, El-Taher et al from Egypt reported the dose rate from environmental radioactivity to be $0.39 \mathrm{mSv} \cdot \mathrm{y}^{-1}(27)$. Recently, Monica et al evaluated the mean indoor AED along the coastal region of Neendakara panchayath, Kelara, and reported it to be $7.56 \mathrm{mSv}^{-\mathrm{y}^{-1}}$ (28).

With regards to the geographical properties, the level of BR was low in the cities of Hormozgan province. In this study, the AED of BR was higher than other cities of this province in Zahedan, Saravan, and Khash in SistanBluchestan province. However, these values were lower than the worldwide mean value of $0.48 \mathrm{mSv}$ reported by UNSCEAR in 2000 (17). These variations are due to effects of altitude, latitude, and distribution of radionuclides on BR measurements. Thus, it can be gathered that altitude and latitude are 2 determining factors for BR levels $(4,29,30)$.

In this study, lifetime cancer risks were computed from the AED values to evaluate the radiological risk. The ELCR calculated from indoor AED in all cities ranged from $0.64 \times 10^{-3}$ to $1.76 \times 10^{-3}$. These values were higher than the world average of ELCR of $0.29 \times 10^{-3}$; therefore, further studies will be required to confirm these results.

Previous studies have found a linear function between altitude and AED from BR $(31,32)$. The altitude parameter has a crucial role in contribution percentage of directly-ionizing particles (eg, electron, proton, and alpha) and photon and neutron components in cosmic rays. At low-altitude regions, the neutron component of the cosmic ray cannot penetrate deeply into the atmosphere to reach the ground. Neutrons reach their maximum dose at the altitude of $10-20 \mathrm{Km}$ above the ground and reduce rapidly to small amounts at sea levels (33). Goldhagen et al (34) measured the neutron flux and its contribution to the total effective dose at high altitude regions. They reported that at high altitude regions, neutrons with energies $>10 \mathrm{MeV}$ contribute to the $24 \%$ of the total fluence rate, $38 \%-39 \%$ of ambient equivalent dose, and $68 \%-70 \%$ of the effective dose rates.

Also, the directly-ionizing components of the cosmic ray are more attenuated at lower altitudes due to attenuation effects of atmosphere layers. It is well established that as altitude of the region is continuing to decrease, the level of BR diminishes concurrently (34). Also, the thin layer of atmosphere and distribution of radionuclides in the higher altitude regions can cause an increase in human exposure. Furthermore, geomagnetic fields result in attenuation of directly-ionizing component of cosmic rays by deflecting low-momentum charged particles back into space (34). The findings of this study indicated that Zahedan, Saravan, and Khash in SistanBluchestan province had relatively high BR, which can be attributed to their high altitude. Another reason can be magnetic highlands in these areas and existence of radionuclides around the mountain ranges. However, more research should be done to investigate this topic by gamma spectrometry of soil samples of this region.

\section{Conclusion}

In conclusion, the aim of this study was to measure BR to compare its level with worldwide data. The results obtained indicated that the study areas had a lower BR level than the worldwide value. This study can be a valuable and useful reference for research design and development of a regional surveys associated with the measurement of natural BR in the southeast of Iran. These data can be used for biological studies such as cancer incidence and hematological studies. 


\section{Conflict of Interests}

The authors declare that they have no competing interests.

\section{References}

1. Ramachandran T. Background radiation, people and the environment. Int J Radiat Res. 2011:9:63.

2. Toosi MB, Haghparast M, Darvish L, Taeb S, Ardekani MA, Dehghani N, et al. Assessment of Environmental Gamma Radiation (Outdoor and Indoor Spaces) in the Region of Bandar Abbas Gachine. J Biomed Phys Eng. 2017. https://doi.org/10.22086/jbpe.v0i0.552

3. Shahbazi-Gahrouei D, Gholami M, Setayandeh S. A review on natural background radiation. Adv Biomed Res. 2013;2: 65

4. Shahbazi-Gahrouei D. Natural background radiation dosimetry in the highest altitude region of Iran. J Radiat Res. 2003;44:285-7.

5. Saghatchi F, Salouti M, Eslami A. Assessment of annual effective dose due to natural gamma radiation in Zanjan (Iran). Radiat Prot Dosimetry. 2008;132:346-9.

6. Ononugbo C, Avwiri G, Tutumeni G. Estimation of indoor and outdoor effective doses from gamma dose rates of residential building in Emelogu village in rivers state, Nigeria. Inter Res J Pure Applied Physic. 2015;3:18-27.

7. Ghiassi-Nejad M, Mortazavi S, Cameron J, Niroomand-Rad A, Karam P. Very high background radiation areas of Ramsar, Iran: preliminary biological studies. Health Phys. 2002;82:87-93.

8. Nair MK, Nambi K, Amma NS, Gangadharan P, Jayalekshmi P, Jayadevan S, et al. Population study in the high natural background radiation area in Kerala, India. Radiat Res. 1999;152:S145-S8.

9. Yang YX, Wu XM, Jiang ZY, Wang WX, Lu JG, Lin J, et al. Radioactivity concentrations in soils of the Xiazhuang granite area, China. Appl Radiat Isot. 2005;63:255-9.

10. Harb S. Natural radioactivity and external gamma radiation exposure at the coastal Red Sea in Egypt. Radiat Prot Dosimetry. 2008; 130:376-84.

11. Pérez M, Chávez E, Echeverría M, Córdova R, Recalde C. Assessment of natural background radiation in one of the highest regions of Ecuador. Radiat Phys Chem. 2018;146:73-6.

12. Abba HT, Hassan WMSW, Saleh MA, Aliyu AS, Ramli AT, Assessment of Terrestrial Gamma Radiation Dose Levels and Isodose Mapping of Some Selected Areas of Jos Plateau, Nigeria. Adv Sci Lett. 2018;24:3592-6.

13. Goddard B, Bosc E, Al Hasani S, Lloyd C. Evaluation of background radiation dose contributions in the United Arab Emirates. J Environ Radioact. 2018;189:191-6.

14. Kaniu M, Angeyo H, Darby I, Muia L. Rapid in-situ radiometric assessment of the Mrima-Kiruku high background radiation anomaly complex of Kenya. J Environ Radioact. 2018;188:47-57.

15. Ramli AT, Aliyu A, Agba E, Saleh M. Effective dose from natural background radiation in Keffi and Akwanga towns, central Nigeria. Int J Radiat Res. 2014;12:47.

16. Kobeissi M, El Samad O, Zahraman K, Rachidi I. Assessment of Indoor and Outdoor Radon Levels in South Lebanon. Int J Disast Risk Sci. 2014; 5:214-226.

17. UNSCEAR (United Nations Scientific Committee on the Effects of Atomic Radiation). 2000. United Nations Scientific Committee on the effects of atomic radiation. Annex A: Exposure from natural sources. New York: United Nations.

18. Ghaffari H, Beik J, Talebi A, Mahdavi SR, Abdollahi H. New physical approaches to treat cancer stem cells: a review. Clin Transl Oncol. 2018;20:1502-21.

19. Tzortzis M, Svoukis E, Tsertos H. A comprehensive study of natural gamma radioactivity levels and associated dose rates from surface soils in Cyprus. Radiat Prot Dosimetry. 2004;109:217-24.

20. Goushbolagh NA, Farhood B, Astani A, Nikfarjam A, Kalantari M, Zare MH. Quantitative Cytotoxicity, Cellular Uptake and Radioprotection Effect of Cerium Oxide Nanoparticles in MRC-5 Normal Cells and MCF-7 Cancerous Cells. Bionanosci. 2018; 8: 769777.

21. Mohanty A, Sengupta D, Das S, Vijayan V, Saha S. Natural radioactivity in the newly discovered high background radiation area on the eastern coast of Orissa, India. Radiat Meas. 2004;38:153-65.

22. Ramli AT, Hussein AWM, Wood AK. Environmental $238 \mathrm{U}$ and 232Th concentration measurements in an area of high level natural background radiation at Palong, Johor, Malaysia. J Environ Radioact. 2005;80:287-304.

23. Mohanty A, Sengupta D, Das S, Saha S, Van K. Natural radioactivity and radiation exposure in the high background area at Chhatrapur beach placer deposit of Orissa, India. J Environ Radioact. 2004;75:15-33.

24. Miles J. Temporal variation of radon levels in houses and implications for radon measurement strategies. Radiat Prot Dosimetry. 2001;93:369-75.

25. Pavlidou S, Koroneos A, Papastefanou C, Christofides G, Stoulos S, Vavelides M. Natural radioactivity of granites used as building materials. J Environ Radioact. 2006;89:48-60.

26. Ajayi OS, Ibikunle SB, Ojo TJ. An assessment of natural radioactivity of soils and its external radiological impact in southwestern Nigeria. Health phys. 2008;94:558-66.

27. El-Taher A, Uosif MA, Orabi AA. Natural radioactivity levels and radiation hazard indices in granite from Aswan to Wadi El-Allaq southeastern desert, Egypt. Radiat Prot Dosimetry. 2007;124:148-54.

28. Monica S, Visnu Prasad A, Soniya S, Jojo P. Estimation of indoor and outdoor effective doses and lifetime cancer risk from gamma dose rates along the coastal regions of Kollam district, Kerala. Radiat Prot Environ. 2016;39:38-43.

29. Radiation UNSCotEoA. Sources and effects of ionizing radiation. UNSCEAR 2000 report to the General Assembly, with scientific annexes. Volume I: Sources. 2000.

30. Bahreyni Toossi M, Bayani S, Yarahmadi M, Aghamir A, Jomehzadeh A, Hagh Parast M, et al. Gonad, bone marrow and effective dose to the population of more than 90 towns and cities of Iran, arising from environmental gamma radiation. Iran J Radiat Res. 2009;7:41-7.

31. Toossi MB, Bayani S, Yarahmadi M, Aghamir A, Jomehzadeh A, Parast $\mathrm{MH}$, et al. Gonad, bone marrow and effective dose to the population of more than 90 towns and cities of Iran, arising from environmental gamma radiation. Iran J Radiat Res. 2009;7:41-7.

32. Sannappa J, Chandrashekara M, Sathish L, Paramesh L, Venkataramaiah P. Study of background radiation dose in Mysore city, Karnataka State, India. Radiat Meas. 2003;37:55-65.

33. Nakamura T, Uwamino Y, Ohkubo T, Hara A. Altitude variation of cosmic-ray neutrons. Health Phys. 1987;53:509-17.

34. Goldhagen P, Reginatto M, Kniss T, Wilson J, Singleterry R, Jones I, et al. Measurement of the energy spectrum of cosmic-ray induced neutrons aboard an ER-2 high-altitude airplane. Nucl Instrum Methods Phys Res A. 2002;476:42-51. 